\title{
Personality Traits, Metabolic Control and the Use of Insulin Pump Functions in Adults With Type 1 Diabetes: An Observational Single-Visit Study
}

\author{
Agnieszka Niemiec · Agata Juruć · Piotr Molęda (D) - Krzysztof Safranow • \\ Lilianna Majkowska
}

Received: October 19, 2020 / Accepted: November 19, 2020 / Published online: December 15, 2020

(C) The Author(s) 2020

\section{ABSTRACT}

Introduction: While a few studies have assessed the association between personality and metabolic outcomes in children and adolescents with type 1 diabetes (T1DM), there have been none in adults or in subjects treated with insulin pumps, and hypoglycaemic episodes have not been considered in these studies. The aim of this observational single-visit study was to assess the association between personality traits and metabolic control, hypoglycaemic episodes and insulin pump use in adult T1DM patients.

Methods: Data were obtained from 52 adults with T1DM treated in a tertiary care centre (no complications or comorbidities; aged

A. Niemiec · P. Molęda ( $₫)$ - L. Majkowska

Department of Diabetology and Internal Diseases, Pomeranian Medical University in Szczecin, Siedlecka 2, 72-010 Police, Poland

e-mail: pmoleda@wp.pl

A. Juruć

State University of Applied Sciences, Przyjaźni 1, 62-510 Konin, Poland

K. Safranow

Department of Biochemistry and Medical Chemistry, Pomeranian Medical University in Szczecin, Powstańców Wielkopolskich 72,

70-111 Szczecin, Poland

\section{A. Niemiec}

Department of Internal Medicine, Independent Public Specialist Health Care Center "Zdroje",

Mączna 4, 70-780 Szczecin, Poland
$27 \pm 8$ years; diabetes duration of $12.8 \pm 6.8$ years; treated with insulin pumps for $6.3 \pm 0.4$ years). "Big Five" personality traits (neuroticism, extraversion, openness, agreeableness and conscientiousness) were assessed using the NEO-Five Factor Inventory questionnaire. Data on $\mathrm{HbA}_{1 \mathrm{c}}$, blood glucose levels, frequency of glucose testing, the number of hypoglycaemic episodes $(<3.9 \mathrm{mmol} / \mathrm{l})$, basal and prandial insulin doses, and the number and types of boluses in the last 14 days were obtained from the insulin pumps and glucometers.

Results: The mean levels of the assessed parameters were: $\mathrm{HbA}_{1 \mathrm{c}} \quad 7.2 \pm 1.2 \%$ $(55.0 \pm 13.1 \mathrm{mmol} / \mathrm{mol})$, episodes of hypoglycaemia 7.0 (3.00-9.75) and glucose tests per day $7.3 \pm 3.9$. All personality traits showed average intensity. None of the traits were associated with $\mathrm{HbA}_{1 \mathrm{c}}$, glycaemia, number of glucose tests, or number or kind of insulin boluses. Conscientiousness was the only factor associated with the incidence of hypoglycaemia in both univariate $(r=+0.46, p<0.001)$ and multivariate $(\beta=+0.41, p<0.001)$ analyses.

Conclusions: Despite results reported for children and adolescents, personality traits of adult patients with T1DM were not essential for metabolic control assessed by $\mathrm{HbA}_{1 \mathrm{c}}$ or for the use of insulin pump functions; however, higher conscientiousness may be related to more frequent hypoglycaemic episodes. Extrinsic factors should be searched as more relevant for 
metabolic control and proper use of very expensive insulin pump therapy.

Keywords: Hypoglycaemic episodes; Insulin pump treatment; Metabolic control; Personality traits; Type 1 diabetes

\section{Key Summary Points}

1. Very few studies have assessed the association between personality traits and metabolic control in children and adolescents with type 1 diabetes (T1DM), but hypoglycaemic episodes have not been considered in these studies, and no one study has been done in adults or in patients treated with insulin pumps.

2. The aim of our study was to assess the association between personality traits and metabolic control, hypoglycaemic episodes and insulin pump use in adult T1DM patients.

3. We found that personality traits of adult T1DM patients were not essential for metabolic control assessed by $\mathrm{HbA}_{1 \mathrm{c}}$ (despite results in children and adolescents) or for the use of insulin pump functions; however, higher conscientiousness may be related to more frequent hypoglycaemic episodes.

4. Extrinsic factors should be searched as more relevant for metabolic control and proper use of very expensive insulin pump therapy.

\section{DIGITAL FEATURES}

This article is published with digital features, including a summary slide, to facilitate understanding of the article. To view digital features for this article go to https://doi.org/10.6084/ m9.figshare.13246670.

\section{INTRODUCTION}

Despite significant advances in therapeutic technology (insulin pens, insulin pumps, and personal devices for glucose monitoring), the metabolic control of type 1 diabetes (T1DM) remains unsatisfactory. Studies conducted in the US and developed European countries have revealed that the mean glycated haemoglobin $\mathrm{HbA}_{1 \mathrm{c}}$ level in patients with T1DM is much higher (approximately 8-9\%) than the values recommended by standards in diabetes care [1-4]. These values are similar to those reported approximately 25 years ago in a DCCT study [5]. The worst metabolic control is observed in adolescents and young adults 18-19 years of age, and $\mathrm{HbA}_{1 \mathrm{c}}$ values improve significantly and reach stable levels in patients at the age of 25-27 years [1]. Therapy with insulin pumps (continuous subcutaneous insulin infusion, CSII) reduces the number of hypoglycaemic episodes and improves the quality of life, but unsatisfactory metabolic control, reflected in high $\mathrm{HbA}_{1 \mathrm{c}}$ levels, remains a problem $[6,7]$.

All subjects with T1DM treated with the CSII method receive care at specialized clinics and attend appropriate training and education sessions. Therefore, insufficient metabolic control is difficult to explain, especially in adults, who are no longer affected by teenage rebellion or by the stress associated with a change of school or transfer from a paediatric outpatient clinic to a clinic for adults.

It cannot be ruled out that handling such a complicated therapy and subsequent adherence to it in everyday life may be affected by the personality. It is well known that personality traits may be associated with the style of learning and motivation to learn and may influence the way in which individuals use electronic devices $[8,9]$.

The analysis of personality usually includes five components. The "Big Five" personality traits (neuroticism, extraversion, openness to experience, agreeableness and conscientiousness) are designed to assess the entire spectrum of personality [10]. The relationship between personality traits and metabolic control in subjects with T1DM has been investigated in very 
few studies conducted only in children and adolescents, and none of these studies included patients who were treated only with insulin pumps [11-13]. Moreover, in these studies, hypoglycaemic episodes were not considered.

Studies assessing personality traits and metabolic control in adults with T1DM have not been reported to date. Because personality traits may change with age and acquired life experience in both healthy subjects and patients with T1DM [14-16], extrapolation of findings from studies of children and adolescents to adults is inappropriate and can lead to erroneous conclusions. This issue is also vital because treatment with insulin pumps is extremely expensive and should provide the best possible results. Assessment of the potential relationship between personality and therapeutic outcomes in adults treated with CSII might be helpful in optimizing the treatment.

The aim of this observational single-visit study was to analyse the association between personality traits in adult subjects with T1DM treated with the CSII method and metabolic control measured by $\mathrm{HbA}_{1 \mathrm{c}}$, the number of hypoglycaemic episodes, glucose self-control and the use of insulin pump functions.

\section{METHODS}

The study included 52 patients with T1DM, 32 females and 20 males aged 18-54 years (mean $27 \pm 8$ years), treated with personal insulin pumps. The participants were recruited from the Outpatient Diabetes Clinic at University Hospital no. 1 in Szczecin, Poland. The centre is a public tertiary care centre taking care of insured adult patients with diabetes, and all the visits were free of charge. The study group consisted of patients with T1DM who were $\geq$ 18 years of age treated with a personal insulin pump. To avoid the effect of diabetes remission on metabolic control, only subjects who had been diagnosed at least 12 months prior to the study were enrolled. All subjects had been treated using CSII for $>6$ months, as it was assumed that this period would help eliminate insufficient experience in the use of the pump. To avoid the potential effects of other factors on metabolic control, we included only subjects who had no diabetes complications or comorbidities Pregnant women were excluded. The study protocol was approved by the Bioethics Committee of Pomeranian Medical University (resolution no. KB-0012/103/17). All procedures followed were in accordance with the ethical standards of the responsible committee on human experimentation (institutional and national) and with the Helsinki Declaration of 1964, as revised in 2013. Participants were enrolled after being given full information on the purpose and the protocol of the study, and all subjects gave written informed consent. During the visit, body weight and height were measured, and body mass index (BMI) was calculated. Blood pressure was measured in the sitting position. Fasting venous blood samples were taken for the measurement of $\mathrm{HbA}_{1 \mathrm{c}}$ (HPLC method, Bio-Rad) and lipid metabolism (total cholesterol, HDL and LDL of cholesterol, triglycerides). At the same visit, each subject completed a questionnaire prepared by the authors. The questions concerned educational level, duration of diabetes, treatment with CSII and duration of care at the diabetes clinic where the study was conducted.

\section{Insulin Pump Treatment and Glucose Monitoring}

Patients were treated with insulin pumps AccuCheck Spirit Combo (Roche Diabetes Care, Basel, Switzerland) or MiniMed Paradigm (715), MiniMed Paradigm REAL-Time (722) or MiniMed Veo (Medtronic, Minneapolis, $\mathrm{MN}$ ) as these pumps were fully refunded by the health care system and used rapid-acting insulin analogues aspart (NovoNordisk), lispro (Ely Lilly) or glulizine (Sanofi-Aventis). All subjects monitored their glucose levels using glucose meters only, and the glucose meters were dedicated to the pump. In the case of the Accu-Chek Spirit Combo pump, it was the Accu-Chek Performa Combo. For the Medtronic pumps glucose meter Contour Plus Link (Ascentia Diabetes Care) was used. In the latter case, each measurement was also transmitted to the pump's memory by Bluetooth. Glucose results can be 
edited while the pump is being read or directly from the meter memory. Regardless of the type of insulin pump used by the patient, records for the 2 weeks prior to the visit were recovered from the device's memory. The following data were acquired: daily dose of insulin (DDI), daily dose of insulin per kilogram of body weight (DDI $/ \mathrm{kg}$ ), percentage of basal insulin and prandial insulin administered in boluses, type of insulin boluses (standard boluses for carbohydrate meals, extended boluses for protein-fat meals and dual-wave boluses for meals containing carbohydrates, proteins and fats) and the frequency of replacement of the infusion set used in subcutaneous insulin delivery. Relevant software was used to access and analyse data from the personal insulin pumps (Smart Pix for Accu-Check from Roche and CareLink Professional for Medtronic Minimed). Data on blood glucose levels, the frequency of blood glucose tests and the number of episodes of hypoglycaemia (glycaemia $<3.9 \mathrm{mmol} / \mathrm{l}$ ) in the last 14 days were obtained from the insulin pumps and from the blood glucose metres.

\section{Personality Traits}

Personality data were gathered using the Polishlanguage version of the NEO-Five Factor Inventory (NEO-FFI), a short version of the NEO-PI-R [17, 18]. The NEO-FFI is a validated, untimed pen-and-paper questionnaire containing 60 descriptive statements designed to assess the Big Five personality traits (neuroticism, extraversion, openness to experience, agreeableness and conscientiousness); each domain is addressed by 12 items. Items are scored on a 5-point scale designed to reflect the participant's score on each item, with scores ranging from 1 (strongly disagree) to 5 (strongly agree). The results were analysed by a psychologist according to the key provided in the Polish adaptation of the textbook for the interpretation of personality traits [17]. The rough scores for the Five-Factor domains were converted into normalized results taking into account the average results in a given population and the age and sex of the subjects. The final results are shown on a 1-10 point scale. The level of each personality trait is defined by the numerical and descriptive method; a score of $1-3$ points indicates a low level of the trait, a score of 4-6 indicates a moderate level, and a score of 7-10 indicates a high level.

\section{Statistical Analysis}

Since distributions of many of the analysed quantitative parameters were significantly different from normal distribution $(p<0.05$, Shapiro-Wilk test), the non-parametric MannWhitney test and Spearman's rank correlation coefficient $\left(r_{S}\right)$ were used in the univariate analysis. Fisher's exact test was used to compare qualitative variables. The multivariate analysis was performed with a general linear model (GLM) after logarithmic transformation of the non-normally distributed variables, and the standardized $\beta$ was presented as the measure of association. $p<0.05$ was considered statistically significant. The statistical power of the study with 52 subjects was sufficient to detect actual differences in NEO-FFI scores between groups stratified according to $\mathrm{HbA}_{1 \mathrm{c}}$ concentration ( $\geq 7 \%$ vs. $<7 \%$ ) equal to 1.6 points with $80 \%$ probability, assuming a standard deviation of 2 points for each NEO-FFI domain and a similar number of patients in each $\mathrm{HbA}_{1 \mathrm{c}}$ group.

\section{RESULTS}

The characteristics of the study group, including history of diabetes, insulin pump treatment and current metabolic control (mean $\mathrm{HbA}_{1 \mathrm{c}}$ level $7.2 \pm 1.2 \%$; $55.0 \pm 13.1 \mathrm{mmol} / \mathrm{mol}$ ), are presented in Table 1. Data on the mode of insulin pump therapy, frequency of glucose selfmonitoring and number of hypoglycaemic episodes are presented in Table 2. Further analysis was performed for the group of patients with satisfactory metabolic control, defined as $\mathrm{HbA}_{1 \mathrm{c}}<7 \%(<53 \mathrm{mmol} / \mathrm{mol})$, and for group with non-satisfactory metabolic control $\left(\mathrm{HbA}_{1 \mathrm{c}} \geq 7 \%(\geq 53 \mathrm{mmol} / \mathrm{mol})\right)$ [19]. Satisfactory control was found in 24 subjects with a mean $\mathrm{HbA}_{1 \mathrm{c}}$ of $6.2 \pm 0.5 \% \quad(44 \pm 5.5 \mathrm{mmol} /$ mol). Non-satisfactory control was observed in 28 subjects with a mean $\mathrm{HbA}_{1 \mathrm{c}}$ of $8.1 \pm 0.8 \%$ 
Table 1 Characteristic of subjects with type 1 diabetes treated with personal insulin pumps; total group and subgroups stratified according to $\mathrm{HbA}_{1 \mathrm{c}}$ levels

\begin{tabular}{|c|c|c|c|c|}
\hline Parameter & $\begin{array}{l}\text { Total } \\
\text { group }\end{array}$ & $\mathrm{HbA}_{1 \mathrm{c}}<7 \%$ & $\mathrm{HbA}_{1 \mathrm{c}} \geq 7 \%$ & $p^{*}$ \\
\hline$N$ & 52 & 24 & 28 & \\
\hline Sex F/M $(n)$ & $32 / 20$ & $15 / 9$ & $17 / 11$ & ns \\
\hline Age (years) & $27.0 \pm 8.0$ & $27.6 \pm 6.8$ & $26.6 \pm 9.2$ & 0.250 \\
\hline Diabetes duration (years) & $12.8 \pm 6.8$ & $13.7 \pm 8.0$ & $12.0 \pm 5.6$ & 0.295 \\
\hline $\begin{array}{l}\text { Duration of treatment in diabetes outpatient clinic for adults } \\
\text { (years) }\end{array}$ & $5.3 \pm 4.7$ & $5.4 \pm 4.3$ & $5.2 \pm 5.1$ & 0.656 \\
\hline Insulin pump treatment (years) & $6.3 \pm 4.0$ & $5.8 \pm 4.1$ & $6.8 \pm 4.0$ & 0.338 \\
\hline BMI $\left(\mathrm{kg} / \mathrm{m}^{2}\right)$ & $24.2 \pm 3.4$ & $23.7 \pm 3.2$ & $24.5 \pm 3.5$ & 0.452 \\
\hline $\mathrm{SBP}(\mathrm{mmHg})$ & $123 \pm 11$ & $125 \pm 12$ & $121 \pm 10$ & 0.232 \\
\hline DBP $(\mathrm{mmHg})$ & $77 \pm 8$ & $76 \pm 8$ & $77 \pm 9$ & 0.390 \\
\hline $\mathrm{HbA}_{1 \mathrm{c}}(\%)$ & $7.2 \pm 1.2$ & $6.2 \pm 0.5$ & $8.1 \pm 0,8$ & $<0.0001$ \\
\hline $\mathrm{HbA}_{1 \mathrm{c}}(\mathrm{mmol} / \mathrm{mol})$ & $55 \pm 13.1$ & $44 \pm 5.5$ & $65 \pm 8.7$ & $<0.0001$ \\
\hline Average glycaemia in last 14 days $(\mathrm{mmol} / \mathrm{l})$ & $8.5 \pm 1.9$ & $7.7 \pm 1.6$ & $9.2 \pm 1.8$ & $<0.001$ \\
\hline Total cholesterol $(\mathrm{mmol} / \mathrm{l})$ & $4.4 \pm 1.0$ & $4.3 \pm 0.8$ & $4.5 \pm 1.1$ & 0.682 \\
\hline HDL-cholesterol $(\mathrm{mmol} / \mathrm{l})$ & $1.8 \pm 0.4$ & $1.7 \pm 0.4$ & $1.8 \pm 0.4$ & 0.131 \\
\hline LDL-cholesterol $(\mathrm{mmol} / \mathrm{l})$ & $2.5 \pm 0.8$ & $2.5 \pm 0.5$ & $2.6 \pm 1.0$ & 0.935 \\
\hline Triglycerides (mmol/l) & $0.8 \pm 0.3$ & $0.8 \pm 0.3$ & $0.9 \pm 0.3$ & 0.304 \\
\hline
\end{tabular}

$B M I$ body mass index, $S B P$ systolic blood pressure, $D B P$ diastolic blood pressure, $H b A_{\text {Ic }}$ glycated hemoglobin, $L D L$ lowdensity lipoprotein, $H D L$ high-density lipoprotein. Data presented as mean \pm standard deviation $n s$ statistically non significant

${ }^{*}$ Mann-Whitney test for quantitative variables and Fisher's exact test for qualitative ones

$(65 \pm 8.7 \mathrm{mmol} / \mathrm{mol})$. The characteristics of both subgroups are shown in Tables 1 and 2 . Both groups were similar in demographic, anthropometric and laboratory parameters. The duration of diabetes, time of insulin pump therapy, time of care at the same outpatient clinic, daily dose of insulin and frequency of infusion set replacement were also similar. Patients with $\mathrm{HbA}_{1 \mathrm{c}}<7 \%$ used significantly less basal insulin and more bolus insulin, but there were no differences in the number or kind of boluses. There was no significant difference in the number of hypoglycaemic episodes in the two subgroups. A significant negative association was observed for the entire group when the incidences of hypoglycaemic episodes and $\mathrm{HbA}_{1 \mathrm{c}}$ were analysed as quantitative variables $\left(r_{S}-0.33, p=0.015\right)$. The number of blood glucose tests performed per day was significantly higher in patients with better metabolic control $(p<0.005)$. More frequent glucose measurements (transformed logarithmically) were the only independent factor associated with lower $\mathrm{HbA}_{1 \mathrm{c}}$ values; this was demonstrated through univariate analysis $\left(r_{S}=-0.44\right.$, $p=0.001)$ and through a multivariate analysis that considered other independent variables such as age, sex, duration of diabetes and 
Table 2 Insulin therapy, glucose monitoring and hypoglycaemic episodes in adult patients with type 1 diabetes treated with personal insulin pumps; total group and subgroups stratified according to $\mathrm{HbA}_{1 \mathrm{c}}$ levels

\begin{tabular}{|c|c|c|c|c|}
\hline Parameter & Total group & $\mathbf{H b A}_{1 \mathrm{c}}<7 \%$ & $\mathrm{HbA}_{1 \mathrm{c}} \geq 7 \%$ & $p^{* *}$ \\
\hline$N$ & 52 & 24 & 28 & \\
\hline Daily dose of insulin (IU/day) & $46.0 \pm 17.0$ & $43.0 \pm 16.8$ & $48.7 \pm 16.9$ & 0.217 \\
\hline Daily dose of insulin $/ \mathrm{kg}(\mathrm{IU} / \mathrm{kg})$ & $0.63 \pm 0.18$ & $0.60 \pm 0.20$ & $0.70 \pm 0.20$ & 0.117 \\
\hline Basal daily insulin (\%) & $42 \pm 12$ & $39 \pm 11$ & $46 \pm 12$ & 0.032 \\
\hline Bolus daily insulin (\%) & $58 \pm 12$ & $61 \pm 11$ & $54 \pm 12$ & 0.032 \\
\hline Standard boluses in last 14 days $(n)$ & $75 \pm 26$ & $82.0 \pm 25.7$ & $69.2 \pm 25.8$ & 0.136 \\
\hline Extended boluses in last 14 days* $(n)$ & $0.0(0.00-1.75)$ & $\begin{array}{l}0.0 \\
(0.0-2.75)\end{array}$ & $0.0(0.0-0.0)$ & 0.224 \\
\hline Dual-wave boluses in last 14 days* $(n)$ & $\begin{array}{l}0.0 \\
(0.00-10.75)\end{array}$ & $\begin{array}{l}3.5 \\
\quad(0.0-14.0)\end{array}$ & $0.0(0.0-5.5)$ & 0.191 \\
\hline Blood glucose tests per day $(n)$ & $7.3 \pm 3.9$ & $8.7 \pm 3.5$ & $6.1 \pm 3.8$ & 0.001 \\
\hline $\begin{array}{l}\text { Hypoglycaemic episodes in last } 14 \text { days (glycaemia } \leq 3.9 \mathrm{mmol} / \\
\mathrm{l}^{*}\end{array}$ & $7.0(3.00-9.75)$ & $\begin{array}{l}8.0 \\
(3.5-14.5)\end{array}$ & $5.5(2.0-9.0)$ & 0.129 \\
\hline Change of infusion sets in last 14 days & $4.8 \pm 1.8$ & $4.5 \pm 1.4$ & $5.0 \pm 2.1$ & 0.498 \\
\hline
\end{tabular}

Data presented as mean \pm standard deviation or ${ }^{*}$ as median (interquartile range)

${ }^{* *}$ Mann-Whitney test

duration of CSII therapy as covariates extraversion, openness and agreeableness were $(\beta=-0.33, p=0.039)$. moderate, whereas scores for conscientiousness

Data on the personality traits of subjects acquired from the NEO-FFI questionnaire are presented in Table 3. The levels of neuroticism, ranged from moderate to high. The levels of all personality traits were similar regardless of the degree of metabolic control. Further analysis of

Table 3 Personality traits of adult patients with type 1 diabetes treated with personal insulin pumps, total group and subgroups stratified according to HbAlc levels

\begin{tabular}{lllll}
\hline Parameter & Total group & $\mathbf{H b A}_{\mathbf{1 c}}<\mathbf{7 \%}$ & $\mathbf{H b A}_{\mathbf{1 c}} \mathbf{2} \mathbf{7 \%}$ & $\boldsymbol{p}^{\mathbf{*}}$ \\
\hline$N$ & 52 & 24 & 28 & \\
Neuroticism & $4.5 \pm 2.1$ & $4.6 \pm 2.1$ & $4.4 \pm 2.0$ & 0.656 \\
Extraversion & $5.7 \pm 1.7$ & $5.5 \pm 2.0$ & $5.9 \pm 1.5$ & 0.566 \\
Openness to experience & $4.8 \pm 1.8$ & $4.9 \pm 2.0$ & $4.7 \pm 1.6$ & 0.877 \\
Agreeableness & $5.1 \pm 1.8$ & $4.8 \pm 1.8$ & $5.4 \pm 1.7$ & 0.217 \\
Conscientiousness & $6.5 \pm 2.2$ & $6.5 \pm 2.1$ & $6.6 \pm 2.3$ & 0.834 \\
\hline
\end{tabular}

Intensity of trait: low: 1-3, medium: 4-6, high: 7-10 points. Data presented as mean \pm standard deviation ${ }^{*}$ Mann-Whitney test 
the data for the entire group of 52 patients to assess the relationship between personality traits and $\mathrm{HbA}_{1 \mathrm{c}}$ values did not reveal any correlation $\left(r_{S}<0.15, p>0.3\right.$, Fig. 1$)$. There was no correlation between the assessed personality
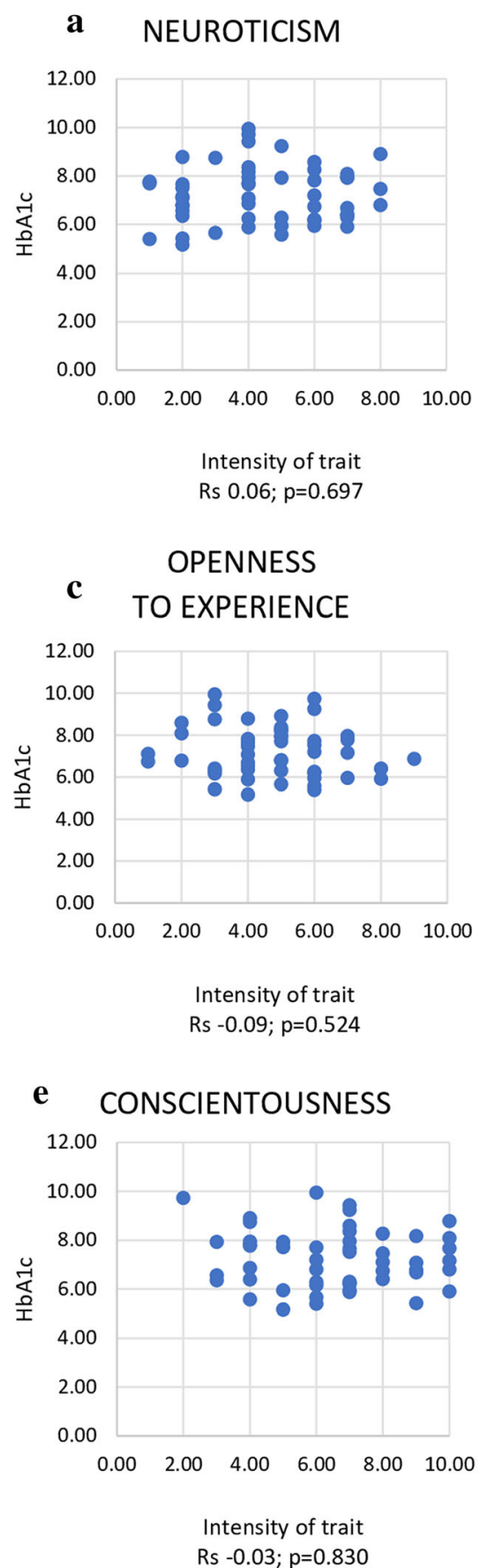

traits and age, duration of diabetes, CSII treatment duration, mean glucose level, number of glucose tests performed, or number or type of boluses. Conscientiousness was the only personality trait associated with the incidence of
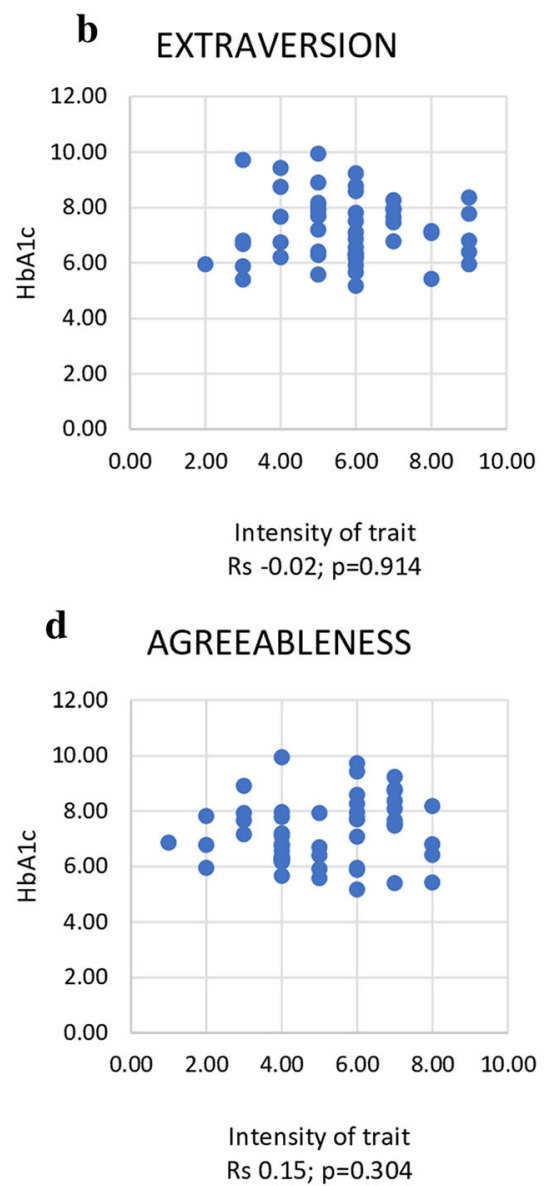
hypoglycaemic episodes. Higher conscientiousness correlated strongly with an increased number of hypoglycaemic episodes in the last 2 weeks $\left(r_{S}=+0.46, p=0.0006\right)$. Higher conscientiousness was also an independent risk factor for frequency of hypoglycaemic episodes (logarithmically transformed) in a multivariate analysis $(\beta=+0.41, p=0.0009)$ that considered age, sex, duration of diabetes, duration of CSII therapy, $\mathrm{HbA}_{1 \mathrm{c}}$ levels and administration of dual-wave boluses as covariates. Dual-wave boluses were included in the analysis because the univariate analysis revealed a significant positive correlation of their frequency with the frequency of hypoglycaemia $\left(r_{S}=0.32\right.$, $p=0.02$ ). The applied multivariate analysis model showed another independent risk factor for hypoglycaemia, i.e., lower HbA1c values ( $\beta=-0.35, p=0.0057)$, while the administration of dual-wave boluses $(\beta=+0.18, p=0.16)$ and other covariates had no significant effect.

Only 29 subjects made a temporary change in basal insulin infusion; the other 23 assessed persons did not use this pump function. The subjects who used this function were characterized by higher levels of extraversion (scores $6.3 \pm 1.7$ vs. $5.0 \pm 1.5, p=0.01)$.

\section{DISCUSSION}

The aim of the present study was to analyse the personality of adult subjects with T1DM treated with CSII and to investigate whether specific personality traits were related to the degree of diabetes control assessed by $\mathrm{HbA}_{1 \mathrm{c}}$ level, number of hypoglycaemic episodes and use of insulin pump functions. The mean age of the patients was approximately 27 years; therefore, they were expected to have stable, fairly good diabetes control. Indeed, the mean $\mathrm{HbA}_{1 \mathrm{c}}$ value for the study group was $7.2 \%$. The 6 -year duration of CSII therapy was much shorter than the mean diabetes duration (13 years) because of the rules regarding the refund system for personal insulin pumps in Poland. The assessed patients had remained under the care of the same clinic for $>5$ years, and this period was long enough to implement similar therapeutic procedures in all of them. This is important for the interpretation of the results, as subjects with type 1 diabetes who were treated in different diabetes care centres showed significant differences in $\mathrm{HbA}_{1 \mathrm{c}}$ values [2].

The analysis of personality traits (neuroticism, extraversion, openness, agreeableness and conscientiousness) in the entire group of subjects revealed moderate levels of each trait. The highest score, between moderate and high, was found for conscientiousness. At the same time, no significant correlation was found between the levels of these personality traits and $\mathrm{HbA}_{1 \mathrm{c}}$ values, mean blood glucose levels, number of blood glucose measurements, or the number or type of prandial boluses. Although one could expect a higher level of conscientiousness in people with lower $\mathrm{HbA}_{1 \mathrm{c}}$, there was no difference in this trait between the subjects with better and worse metabolic control. Very similar data indicating medium or high-medium intensity of five typical personality traits were found in a large group of emerging adults 18-35 years old with T1DM [20]. Data obtained in this study were correlated with age, sex and self-esteem, while parameters of metabolic control or way of treatment were not assessed.

The results of our study in adult patients with type 1 diabetes treated with CSII are in contrast to earlier studies conducted only in children and very young subjects [11-13]. Findings in children and adolescents $<16$ years of age with T1DM observed for 2 years from the time of diagnosis found that lower $\mathrm{HbA}_{1 \mathrm{c}}$ levels were associated with greater conscientiousness and agreeableness in the case of both the patients and their mothers [11]. A study of 28 adolescents aged 13-18 years also found a potential relationship between conscientiousness, neuroticism and the course of therapy [12]. The results of the latter study are difficult to interpret because the relationships between personality traits and diabetes control were based only on the $\mathrm{HbA}_{1 \mathrm{c}}$ values reported by the patients. Another observation of children and adolescents 8-19 years of age with T1DM showed that greater conscientiousness and agreeableness were associated with lower and more stable $\mathrm{HbA}_{1 \mathrm{c}}$ values at the 3-year follow-up [13]. Surprisingly, this relationship was not reported in the first year but only in the second 
and third years of observation, while the levels of personality traits remained stable throughout this period. These data indicate that extrinsic factors may have a greater impact than personality on patients' behaviour and actions. It is necessary to stress that none of the compared studies were conducted in CSII-treated patients. It was shown that the personality of close relatives (mothers of children and adolescents, or spouses of adults) may influence diabetes control and outcome achievement [11, 21]. A recent study demonstrated that persons with T1DM treated by "less agreeable" doctors had lower $\mathrm{HbA}_{1 \mathrm{c}}$ levels [22]. Socioeconomic factors may also affect the metabolic control of T1DM $[23,24]$. The accumulation of illness-specific and environmental stressors may impact the complex regimen of diet, blood glucose monitoring and insulin administration. Insulin pump therapy requires great attention and may increase stress levels. Coping with stress in T1DM patients on insulin pumps may be of much greater importance than other personality traits. The relationship between coping strategies and metabolic control and self-glucose monitoring in DM1 people treated with insulin pumps was assessed recently [25]. Unfortunately, $\mathrm{HbA}_{1 \mathrm{c}}$ levels in the cited study were only reported by the patients, and there are no data concerning frequency of hypoglycaemia or the use of insulin pump functions.

Conscientiousness was the only personality trait that showed a very strong correlation with hypoglycaemic episodes. This study is the first to report such a relationship in T1DM subjects, as previous studies did not consider hypoglycaemia [11-13]. Conscientiousness includes traits such as orderliness, self-efficacy, self-discipline, dutifulness, achievement striving and cautiousness. A high level of conscientiousness is linked with a tendency to keep things in order and perfectionism [18]. In the treatment of diabetes, it can lead to precise, sometimes excessive control of glycaemia, and this may result in more frequent episodes of hypoglycaemia.

It may be that proper education plays the most important role in subjects with T1DM treated with CSII, and education should be provided appropriately from the very beginning of the disease [26]. Patients received care at our centre only for a portion of their time with diabetes, so it cannot be ruled out that the subjects with different degrees of metabolic control had been somewhat differently educated at the time of diagnosis and during the first years of treatment. Our observation that the frequency of self-control tests was strongly associated with better metabolic control but not related to any of personality traits seems to support the idea that education might be most important.

The mean number of glucose tests performed per day was nine in subjects with better diabetes control. This result is consistent with the findings of the study in which the lowest $\mathrm{HbA}_{1 \mathrm{c}}$ values, in both paediatric and adult subjects with T1DM, were found in individuals who tested their glucose levels at least ten times per day [1]. The role of the number of glucose tests is evidenced by the results of continuous glucose monitoring (CGM), particularly in adults aged $\geq 26$ years [27-29]. Unfortunately, in many countries, CGM systems are not available for most adult patients. Due to the refund system, this was the case for our patients. As we wanted to assess their personality and metabolic control in routine clinical practice, we decided not to perform CGM, as it would have been an unusual intervention and may have changed the patients' behaviours, patients' decisions and the results of the observation. The subjects from both groups monitored their glucose levels using glucose meters only, and it is possible that some episodes of hypoglycaemia were not detected. However, this should not be crucial for the interpretation of the obtained results.

The relationship between the use of insulin pump functions and personality traits observed in our study was very weak and indicated only the possibility of some role of extraversion.

Our study has some limitations. One of them is the relatively small number of investigated subjects, but in the observational single-visit studies with very long, time-consuming questionnaires and the assessment of many other factors involving patients' attention it is difficult to gather a bigger group of participants. However, the statistical power of the study with 52 subjects was sufficient for proper analysis. 
The other limitation of the study was a lack of information on socioeconomic status (marital, family and working status, incomes) which could interfere with and even detract from proper diabetes management. The lack of CGM is also important as we did not have data on time in range for glucose levels and on real frequency of hypoglycaemic episodes. However, using an extraordinary device, not used in everyday life, might change the final results of the study.

To the best of our knowledge, this study was the first to assess the relationship between personality traits, diabetes control and the use of insulin pump functions in adults with T1DM treated with the CSII method. In contrast to earlier reports in children and adolescents, our study did not reveal any association between personality and metabolic control based on $\mathrm{HbA}_{1 \mathrm{c}}$ levels. Higher conscientiousness was the only strong independent risk factor for episodes of hypoglycaemia. This is the first time this relationship has been reported in T1DM patients, as previous studies did not consider hypoglycaemia. Personality traits also did not seem to be very important for the use of insulin pump functions. It is possible that extrinsic factors such proper education starting from the initial diabetes diagnosis, family status and socioeconomic factors may be much more relevant.

\section{CONCLUSIONS}

Despite results reported for children and adolescents, personality traits of adult patients with T1DM were not essential for metabolic control assessed by $\mathrm{HbA}_{1 \mathrm{c}}$ or for the use of insulin pump functions; however, higher conscientiousness may be related to more frequent hypoglycaemic episodes. Extrinsic factors should be searched as more relevant for metabolic control and proper use of very expensive insulin pump therapy.

\section{ACKNOWLEDGEMENTS}

We thank the participants of the study.
Funding. Study: Pomeranian Medical University (WNoZ 323/01/S/17), Szczecin, Poland. Journal's Rapid Service Fee: Pomeranian Medical University, Szczecin, Poland.

Authorship. All authors read and approved the final version of the manuscript prior to submission. All named authors meet the International Committee of Medical Journal Editors (ICMJE) criteria for authorship for this article, take responsibility for the integrity of the work as a whole, and have given their approval for this version to be published.

Authorship Contributions. Niemiec A. contributed to the study design, carried out the acquisition and analysis of the data, and performed the drafting of the manuscript. Juruć A. contributed to the study design and provided advice for the analysis. Moledda P. participated in the study design and helped revise the manuscript. Safranow K. provided statistical advice and reviewed the manuscript. Majkowska L. designed the study, provided advice and cowrote the manuscript.

Disclosures. Agnieszka Niemiec, Agata Juruć, Piotr Molęda, Krzysztof Safranow and Lilianna Majkowska have nothing to disclose.

Compliance with Ethics Guideline. The study protocol was approved by the Bioethics Committee of Pomeranian Medical University, Szczecin, Poland; decision KB-0012/103/17. All authors confirm that the study was performed in accordance with the Helsinki Declaration of 1964 and its later amendments. Participants were enrolled after being given full information on the purpose and the protocol of the study, and all subjects provided a written informed consent to participate in the study.

Data Availability. The datasets generated during and/or analyzed during the current study are available from the corresponding author on reasonable request.

Open Access. This article is licensed under a Creative Commons Attribution-NonCommercial 4.0 International License, which permits 
any non-commercial use, sharing, adaptation, distribution and reproduction in any medium or format, as long as you give appropriate credit to the original author(s) and the source, provide a link to the Creative Commons licence, and indicate if changes were made. The images or other third party material in this article are included in the article's Creative Commons licence, unless indicated otherwise in a credit line to the material. If material is not included in the article's Creative Commons licence and your intended use is not permitted by statutory regulation or exceeds the permitted use, you will need to obtain permission directly from the copyright holder. To view a copy of this licence, visit http://creativecommons.org/licenses/by$\mathrm{nc} / 4.0 /$.

\section{REFERENCES}

1. Miller KM, Foster NC, Beck RW, et al. Current state of type 1 diabetes treatment in the US: updated data from the T1D Exchange Clinic Registry. Diabetes Care. 2015;38:971-8.

2. Gerstl EM, Rabl W, Rosenbauer J, et al. Metabolic control as reflected by HbA1c in children, adolescents and young adults with type 1 diabetes mellitus: combined longitudinal analysis including 27 035 patients from 207 centers in Germany and Austria during the last decade. Eur J Pediatr. 2008;167:447-53.

3. Foster NC, Beck RW, Miller KM, et al. State of type 1 diabetes management and outcomes from the T1D Exchange in 2016-2018. Diabetes TechnolTher. 2019;21:66-72.

4. Charalampopoulos D, Hermann JM, Svensson J, et al. Exploring variation in glycemic control across and within eight high-income countries: a crosssectional analysis of 64,666 children and adolescents with type 1 diabetes. Diabetes Care. 2018;41: 1180-7.

5. Diabetes Control and Complication Trial Research Group, Nathan DM, Genuth S, Lachin J, et al. The effect of intensive treatment of diabetes on the development and progression of long term complications in insulin-dependent diabetes mellitus. N Engl J Med. 1993;329:977-86.

6. Misso ML, Egberts KJ, Page M, OConnor D, Shaw J. Continous subcutaneous insulin infusion (CSII) versus multiple insulin injections for type 1 diabetes mellitus. Cochrane Database Syst Rev. 2010;1:005103.

7. Thabit H, Hovorka R. Continuous subcutaneous insulin infusion therapy and multiple daily insulin injections in type 1 diabetes mellitus: a comparative overview and future horizons. Expert Opin Drug Deliv. 2016;13:389-400.

8. Komarraju M, Karau SJ, Schmeck RR, Avdic A. The big five personality traits, learning styles, and academic achievement. PersIndividDif. 2011;51:472-7.

9. Phillips JG, Butt S, Blaszczynski A. Personality and self reported mobile phone use for games. Cyberpsychology. 2006;9:753-8.

10. John OP, Srivastava S. The Big Five traits taxonomy: history, measurement and theoretical perspectives. In: Pervin LA, John OP, editors. Handbook of personality: theory and research. 2nd ed. New York: Guilford Press; 1999. p. 102-38.

11. Vollrath ME, Landolt MA, Gnehm HE, Laimbacher J, Sennhauser FH. Child and parental personality are associated with glycaemic control in type 1 diabetes. Diabetes Med. 2007;24:1028-33.

12. Wheeler K, Wagaman A, McCord D. Personality traits as predictor of adherence in adolescents with type 1 diabetes. J Child AdolescPsychiatrNurs. 2012;25:66-74.

13. Waller D, Johnston C, Molyneaux L, et al. Glycemic control and blood glucose monitoring over time in a sample of young Australians with type 1 diabetes. Diabetes Care. 2013;36:2968-73.

14. Specht J, Egloff B, Schmukle SC. Stability and change of personality across the life course: the impact of age and major life events on mean-level and rank-order stability of the Big Five. J PersSocPsychol. 2011;101:862-82.

15. Harris MA, Brett CE, Johnson W, Deary IJ. Personality stability from age 14 to age 77 years. Psychol Aging. 2016;31:862-74.

16. Rassart J, Oris L, Prikken S, Weets I, Moons P, Luyckx K. Personality functioning in adolescents and emerging adults with type 1 diabetes. J Adolesc Health. 2018;63:792-8.

17. Zawadzki B, Strelau J, Szczepaniak P, Śliwińska M, editors. Inwentarzosobowości NEO-FFI Costyi McCrae: adaptacjapolska: podręcznik. Warszawa: Pracownia Testów Psychologicznych Polskiego Towarzystwa Psychologicznego; 1998.

18. Costa PT Jr, McCrae RR. Revised NEO Personality inventory (NEO-PI-R) and NEO-Five-Factor 
inventory (NEO-FFI): professional manual. Odessa: Psychological Assessment Resources; 1992.

19. Targets G. Standards of Medical Care in Diabetes2019. Am Diabetes Assoc Diabetes Care. 2019;42(Suppl 1):S61-70.

20. Novak JR, Anderson JR, Johnson MD, et al. Does personality matter in diabetes adherence? Exploring the pathways between neuroticism and patient adherence in couples with type 2 diabetes. ApplPsychol Health Well Being. 2017;9:207-27.

21. Rassart J, Luyckx K, Moons P, Weets I. Personality and self-esteem in emerging adults with Type 1 diabetes. J Psychosom Res. 2014;76:139-45.

22. Cameron FJ, Russell E, McCombe J, O'Connell MA, Skinner T. The clinician factor: Personality characteristics of clinicians and their impact upon clinical outcomes in the management of children and adolescents with type 1 diabetes. Pediatr Diabetes. 2018;19:832-9.

23. Willers C, Iderberg $H$, Axelsen $M$, et al. Sociodemographic determinants and health outcome variation in individuals with type 1 diabetes mellitus: a register-based study. PLoS ONE. 2018;13:e0199170.

24. Gesuita R, Skrami E, Bonfanti R, et al. The role of socio-economic and clinical factors on HbA1c in children and adolescents with type 1 diabetes: an
Italian multicentre survey. Pediatr Diabetes. 2017;18:241-8.

25. Bisio A, Gamarra E, Broglio F, Grassi G. Coping strategies in people with type 1 diabetes on insulin pump treatment. Minerva Endocrinol. 2019;44: 336-43.

26. Araszkiewicz A, Zozulinska-Ziolkiewicz D, Trepinska M, Wierusz-Wysocka B. Knowledge after fiveday teaching program in intensive insulin therapy performed at the onset of type 1 diabetes influence the development of late diabetic complications. Diabetes Res ClinPract. 2008;81:61-7.

27. Šoupal J, Petruželková L, Grunberger G, et al. Glycemic outcomes in adults with T1D are impacted more by continuous glucose monitoring than by insulin delivery method: 3 years of follow-up from COMISAIR Study. Diabetes Care. 2020;43:37-43.

28. Beck RW, Riddlesworth T, Ruedy K, et al. DIAMOND Study Group. Effect of continuous glucose monitoring on glycemic control in adults with type 1 diabetes using insulin injections: the DIAMOND randomized clinical trial. JAMA. 2017;317:371-8.

29. Foster NC, Miller KM, Tamborlane WV, Bergenstal RM, Beck RW. Continuous glucose monitoring in patients with Type 1 Diabetes using insulin injections. Diabetes Care. 2016;39:e81-2. 